\title{
Canine Traditional Laboratory Tests and Cardiac Biomarkers
}

\author{
Alessandra Gavazza ${ }^{1 \star}$, Alessandro Fruganti ${ }^{1}$, Vanessa Turinelli ${ }^{2}$, Andrea Marchegiani ${ }^{1}$, \\ Andrea Spaterna ${ }^{1}$, Beniamino Tesei ${ }^{1}$, Giacomo Rossi ${ }^{1}$ and Matteo Cerquetella ${ }^{1}$ \\ ${ }^{1}$ School of Biosciences and Veterinary Medicine, University of Camerino, Camerino, Italy, ${ }^{2}$ IDEXXX Laboratories-Italia S.r.l, \\ Milan, Italy
}

In small animals, cardiac disease evaluation through laboratory tests can be a challenge. This review will present both historical and updated perspectives on the clinical pathology of cardiac diseases in dogs and demonstrate that laboratory tests are useful tools for the management of patients with cardiac diseases.

Keywords: laboratory test, biomarker, cardiac disease, dog, review

\section{INTRODUCTION}

OPEN ACCESS

Edited by:

Meg M. Sleeper,

University of Florida, United States

Reviewed by:

Domenico Caivano,

University of Perugia, Italy

Eva Sierra,

University of Las Palmas de Gran

Canaria, Spain

*Correspondence:

Alessandra Gavazza

alessandra.gavazza@unicam.it

Specialty section:

This article was submitted to Comparative and Clinical Medicine,

a section of the journal

Frontiers in Veterinary Science

Received: 19 January 2020

Accepted: 11 May 2020

Published: 26 June 2020

Citation:

Gavazza A, Fruganti A, Turinelli V, Marchegiani A, Spaterna A, Tesei B, Rossi G and Cerquetella M (2020)

Canine Traditional Laboratory Tests and Cardiac Biomarkers.

Front. Vet. Sci. 7:320

doi: 10.3389/fvets.2020.00320
"Traditional" tests such as biochemical, hematological, and coagulative profile, urine and feces analysis, blood culture, and effusion analysis may be altered by cardiovascular diseases but are not specific. On the other hand, of great interest is the study of new and specific tests or biomarkers that could provide information about myocardial injury, to be used in investigating and monitoring patients with cardiac disease. In the last few years, specific hematologic biomarkers such as troponin and natriuretic peptides have been studied; similarly, innovative studies concerning fecal proteomics and microbiota in dogs with cardiac disease were published as well.

Results of laboratory tests have to be analyzed considering clinical evolution, clinical signs, and other specific diagnostic evaluations, in order to use a multimodal approach in the evaluation of the pathology and also of the possible complications of any patient.

\section{TRADITIONAL LABORATORY TEST}

"Traditional" parameters of heart damage are those routinely used for general purposes and are therefore not specific, but they can be useful to confirm a cardiopathy and for monitoring and prognostic purposes.

\section{Biochemical Profile}

Creatine kinase (CK), mainly a cytosolic enzyme, is primarily active in skeletal and cardiac muscles and the brain. Three main isoenzymes (CK-BB, CK-MB, CK-MM) can be separated electrophoretically, but only CK-MB is found in the myocardium. Consequently, the increase in total $\mathrm{CK}$ is typically indicative of total muscle damage, not only relative to CK-MB, and unfortunately, plasma CK half-life is under $3 \mathrm{~h}(1,2)$.

Serum aspartate aminotransferase (AST) is a cytosolic and mitochondrial isoenzyme not specific to a tissue; the muscle and liver are its main sources. The amount of the heart muscle is less than that of the skeletal muscle or hepatocyte, and its plasmatic half-life is $\sim 12 \mathrm{~h}$ in dogs $(1,2)$. Lactate dehydrogenase $(\mathrm{LDH})$ is a ubiquitous cytosolic enzyme, although muscle, liver, and erythrocyte damages could be responsible for an increase in serum activity. LDH has five isoenzymes (LDH1, LDH2, LDH3, LDH4, and LDH5) separable by electrophoresis, and LDH1 is most represented in the heart and kidney. Unfortunately, electrophoretic separation is not 
routinely done in daily practice and therefore total $\mathrm{LDH}$ is usually dosed. LDH half-life is $<6 \mathrm{~h}(1,2)$. C-reactive protein (CRP) is considered a major acute-phase protein in dogs, and its amount increases in response to inflammation. In humans, CRP is a mediator of inflammation and an indicator of phlogosis. CRP was analyzed for its relation to atherosclerosis, coronary artery disease (CAD), acute coronary syndromes, and heart failure (HF), and it is now considered to play a role in growth and development of $\operatorname{HF}(3,4)$. CRP in dogs may represent a screening test for a lot of conditions, showing high sensitiveness even if not specific in identifying the underlying pathology. It increases in $4 \mathrm{~h}$ following the damage in the dog and reaches a maximum peak in $24-48 \mathrm{~h}$ (5). CRP is possibly an indicator of pulmonary hypertension $(\mathrm{PH})$ and endothelial arteritis in canine patients presenting filariasis, and CRP amount might get higher in dogs with dilated cardiomyopathy (DCM) even earlier than lung vascular alterations are evidenced by thorax radiography and echocardiography. Dogs not presenting filariasis evidenced significantly increased CRP rates when suffering from DCM or $\mathrm{PH}$ (6). With regard to electrolytes and minerals, hyperphosphatemia is associated with reduced glomerular filtration rate (GFR), and in patients suffering from chronic renal failure, the degree of hyperphosphatemia is directly correlated with the degree of azotemia, which may be related to cardiorenal syndrome (CRS). Hypercalcemia is infrequent in nephropathic dogs (7). Likewise, hypokalemia can develop secondary to significant cardiac disease for translocation across the cell membrane brought about by sympathetic stimulation and for renal loss secondary to high aldosterone concentrations. This latter reason is particularly common while treating HF with diuretics $(8,9)$. An acute decrease in renal function with oliguria may instead cause hyperkalemia and acidosis because of impaired renal excretions of cations $\left(\mathrm{K}^{+} \mathrm{H}^{+}\right)(10)$. On the other hand, the most common cause of moderate to marked hyponatremia in dogs is advanced congestive HF with or without concomitant diuretic therapy (9).

\section{Cardiorenal Syndrome}

"CRS" has been reported in humans as "disorders of the heart and kidneys whereby acute or chronic dysfunction in one organ may induce acute or chronic dysfunction of the other" (11-13). The CRS Consensus Group attempted to reach a consensus in defining canine "cardiovascular-renal disorders" (CvRD) as well as in interpreting the pathophysiology, diagnosis, and management of the condition (14). The cardiorenal axis is the bond between canine chronic heart failure (CHF) and renal insufficiency (RI). When the presence of non-protein nitrogenous compounds,

Abbreviations: ANP, Atrial natriuretic peptide; AST, Aspartate aminotransferase; BNP, B-type natriuretic peptide; CRP, C reactive protein; cTnT, Cardiac troponin-T; CRS, Cardio renal syndrome; CvRD, Cardiovascular-renal disorders; CHF, Chronic heart failure; CKD, Chronic kidney disease; CVD, Chronic valvular disease; CAD, Coronary artery disease; CK, Creatine kinase; DCM, Dilated cardiomyopathy; GFR, Glomerular filtration rate; HF, Heart failure; $\mathrm{Hb}$, Hemoglobin; NTproANP or NTproBNP, Inactive N-terminal fragments; LDH, Lactate dehydrogenase; MVD, Mitral valve disease; PCV, Packed cell volume; NT-proBNP, Pro B-type natriuretic peptide; $\mathrm{PH}$, Pulmonary hypertension; RDW, Red blood cell distribution width; RI, Renal insufficiency; SDMA, Symmetric dimethylarginine; USG, Urine specific gravity. mainly urea and creatinine, increases in blood, it is reported as azotemia (15). Azotemia is high in dogs suffering from chronic valvular disease (CVD), and the risk of azotemia increases with HF severity. The correlation found between ACVIM and both blood urea nitrogen (BUN) and creatinine (CREA) is of clinical importance while treating patients with serious heart disease. Whether the decline in renal function is the consequence of cardiac disease evolution must still be demonstrated $(16,17)$.

The determination of BUN, CREA, and symmetric dimethylarginine (SDMA) together with urinalysis is necessary for the identification of CRS. Urea is a product of protein metabolism and is excreted via the renal system; therefore, in case of shock, dehydration, cardiovascular disease, etc., in which the GFR decreases, it results in a growth of BUN concentration (10).

CREA is filtered by the glomerulus, and there is no tubular reabsorption. Serum creatinine is a better marker than BUN for GFR, as it is not reabsorbed and is minimally secreted in tubules; obviously, a reduced GFR affects CREA similarly to BUN (10). Finally, SDMA is a sensitive and specific marker of renal function. Serum SDMA levels increase as kidney function and GFR decline. SDMA evaluations in patients suffering from chronic kidney disease (CKD) demonstrated that its concentration increases in dogs up to months earlier than CREA; it, in fact, increases when the GFR is reduced up to $40 \%$, whereas CREA level increases later, with GFR reduction higher than 75\% (18).

\section{Hematological Profile}

In human, the contemporary presence of HF, RI, and anemia determines a clinical triangle called cardiorenal anemia syndrome in which $\mathrm{HF}$ and RI can adversely affect each other and their mutual worsening increased with anemia (19). The pathophysiology of anemia related to HF is caused by many factors and includes renal imbalance and reduced erythropoietin production (19), increased production of proinflammatory cytokines like interleukins and tumor necrosis factor $(20,21)$, increase in plasma volume (22), and lower production of erythropoietin (23).

In dogs, a study that includes 114 cases of mitral valve disease (MVD) revealed that hemoglobin $(\mathrm{Hb})$ amount and packed cell volume (PCV) reduced with growing seriousness of the condition and that anemia was related with a worse result, emerging as a forecast of mortality. Anemia was also related with HF seriousness and blood creatinine increase, leading the authors to hypothesize the existence of a cardiorenal anemia syndrome similar to what happens in humans (24).

Another study observed in dogs with CVD showed that $\mathrm{Hb}$ was negatively correlated with CREA and International Renal Interest Society stage, confirming the existence of a link between renal impairment degree and anemia, but no correlation was found between anemia and classes of $\operatorname{HF}(16,25)$.

Red blood cell distribution width (RDW) quantitatively measures anisocytosis, and in humans it is considered a widely available marker, able to predict adverse outcomes in leftsided HF $(26,27)$. RDW is also related with fatal outcome in patients with $\mathrm{PH}$. In a recent review, it was suggested that augmented RDW value is related with acute coronary syndrome, 
cerebrovascular ischemia, and peripheral artery disease, as well as atrial fibrillation, hypertension, and HF (28). Furthermore, a high level of anisocytosis is an important prediction of worse results in patients with these conditions (28). In man, it has been shown in 162 subjects, $62 \%$ having $\mathrm{PH}$, that RDW turned out to be related with fatal outcome if serious $\mathrm{PH}$ was also present and that it worked more properly as a prognostic indicator rather than the N-terminal fragment of pro B-type natriuretic peptide (NT-proBNP) (see later) (29).

In dogs, a study compared RDW in 44 patients suffering from $\mathrm{PH}$ due to different causes; more precisely, post-capillary hypertension was present in 16 of them (caused by left-sided cardiac disease) and pre-capillary hypertension in 28 (caused by primary respiratory disease, pulmonary vascular disease, and idiopathic forms). It demonstrated that RDW is highly different among dogs suffering from pre-capillary $\mathrm{PH}$ and controls; however, no significant differences were found between patients showing post-capillary $\mathrm{PH}$ and controls. There was a similar proportion of survival rate among dogs gathered depending on RDW values, but RDW did not properly predict $\mathrm{PH}$ seriousness (30).

Chronic cardiac and pulmonary disease in dogs, resulting in dyspnea from impaired oxygen transfer, may lead to an appropriate secondary erythrocytosis $(31,32)$. In physiologically appropriate erythrocytosis, the erythropoietin-mediated increased erythrocyte mass expands the hematic oxygencarrying capacity in attempt to improve inadequate tissue oxygenation. Congenital heart anomalies, e.g., tetralogy of Fallot, cause delivery of poorly oxygenated blood to the systemic circulation with resultant erythrocytosis $(32,33)$. In addition, in canine patients presented with congestive heart failure, it was shown that poikilocytosis, which is a general term for variation in $\mathrm{RBC}$ shape, resulted from oxidative damage; it is a non-specific observation as occurring in a variety of conditions. In particular, in dogs with congestive heart failure (and glomerulonephritis), keratocyte (spiculated RBCs that frequently have only 1-2 spicules and indicate RBC fragmentation) and schistocyte (red blood cell fragments usually resulting from direct physical damage to RBCs) can be found $(34,35)$.

Congenital dyserythropoiesis, polymyopathy, and cardiac disease (cardiomegaly) were reported in three related English Springer Spaniels. All dogs presented microcytic normochromic non-regenerative anemia associated with marked metarubricytosis. Alterations in RBC morphology such as spherocytes, schistocytes, dacryocytes, codocytes, and vacuolated RBC were also present (36).

Also, changes in white blood cell type and number may be seen in inflammatory cardiovascular disease. Bacterial endocarditis is typically associated with leukocytosis, monocytosis, neutrophilia, and a left shift. Leukocytosis and thrombocytopenia have been reported to be present in nearly $90 \%$ of patients in a case series of dogs with inflammatory cardiovascular disease (37).

\section{Coagulative Profile}

People with chronic heart failure show increased thrombin activity, fibrinolytic activity, and platelet activation $(38,39)$. In a study involving canine patients suffering from CHF, mainly Cavalier King Charles Spaniels, fibrinogen, Ddimer, and thrombin-anti-thrombin complex concentrations, contrary to anti-thrombin and protein $\mathrm{C}$ activity, were, respectively, increased and lowered compared with controls. This data suggests the presence of a procoagulant and overt thromboembolism state in $\mathrm{CHF}$ cases. The five hemostatic biomarkers abovementioned were not found to be predictors of mortality (40).

In addition, MVD is related with enhanced reactivity and decreased persistence of platelets in patients, and a possible association between MVD and platelet dysfunction has also been investigated in dogs, particularly in Cavalier King Charles Spaniels. One study carried out in two subgroups of Cavalier King Charles Spaniels presenting prolapsing mitral valves evidenced that one group, which comprehends $<100.000$ platelets $\mu \mathrm{L}$, had usual platelet aggregation and enlarged platelets, while the second group, which contains more than 100.000 platelets/ $\mu \mathrm{L}$, showed augmented platelet aggregation and standard platelet size (41).

Another study on Cavalier King Charles Spaniels with various grades of mitral valve regurgitation showed that dogs may have a decreased platelet function but not an increased platelet reactivity. The structure of the mechanism behind the reduction in platelet activity is still not clear, but an activation followed by a deactivation of platelets, due to recurrent high shear stress, may represent the underlining cause (42). A further study found that Cavalier King Charles Spaniels with mitral valve prolapse had enhanced aggregation responses regardless of mitral regurgitation status, but platelets were not circulating in an activated state. In that study, Cavalier King Charles Spaniels with mitral regurgitation (MR) and dogs presenting subaortic stenosis had prolonged platelet function tests [platelet function analyzer (PFA) -100 closure times]. Also, they had lower proportions of large von Willebrand factor (VWF) multimers suggesting a mechanism of impaired primary hemostasis, different from platelet hypofunction (43).

\section{Urinalysis}

This exam is useful to understand the degree of involvement of the heart and kidneys in the presence of a CRS. In cardiorenal axis, the existing link among CHF and RI in dogs could be confirmed by urinalysis. Urine-specific gravity (USG) determined by refractometry allows assessment of renal concentrating ability. Interpretation of CREA in combination with USG can help to determine whether azotemia is renal or non-renal. However, it is frequently difficult to judge whether elevation of urea and/or creatinine in patients with heart disease is due to intrinsic renal disease or pre-renal azotemia. USG in azotemic patients with cardiovascular disease not undergoing any therapy may help to differentiate concurrent primary renal disease from pre-renal azotemia as consequence of reduced blood flow. In such a case of pre-renal azotemia, USG is usually $>1,030$, while when azotemia is renal, the USG is usually between 1,007 and 1,013. Unfortunately, USG cannot be used in many patients to distinguish between these two conditions because they are often receiving diuretics, which reduces its value $(7,8,10)$. 
Proteinuria must be interpreted simultaneously to USG. Measuring the urine protein creatinine ratio is useful to define the magnitude and, for this reason, the impact of proteinuria. Cardiac disease and other extrarenal issues can possibly trigger a transitory mild pre-renal proteinuria through increased glomerular permeability $(7,44)$.

No specific markers for CvRD are presently available, and their research, together with that of markers for CRS and for novel renal damage biomarkers, is a topic which can be substantial and of significant interest in both man and animals (14).

\section{Blood Culture}

Endocarditis is a condition usually associated with bacteremia normally involving aortic and/or mitral valves; bacteria present in the blood flow directly contaminate the endocardial surface. Bacterial endocarditis can be reasonably diagnosed following more than two positive blood cultures (45-47).

The most commonly reported etiologic agents are streptococci, staphylococci, gram-negative bacilli, and Bartonella spp., while anemia, leukocytosis, thrombocytopenia, hypoalbuminemia, increased liver enzyme activity, and azotemia are frequent laboratory findings (48). Even with optimal sample collection, blood cultures may be negative in patients who are very strongly suspected of being bacteremic or having bacterial endocarditis, as shown by a retrospective study in which the causative organism was identified in only $58 \%$ of patients with endocarditis. One reason, in some cases, is reported as the possible prior administration of antibiotics before sample collection $(8,37,48)$.

\section{Effusion Analysis}

The abnormal collection of fluids within body cavities (effusion) is a possible finding during $\mathrm{HF}$, and ascites (fluids in the abdomen) is seen more frequently with right-heart failure in dogs, as a consequence of acquired diseases (e.g., tricuspid regurgitation due to endocardiosis, heartworm disease, dilated cardiomyopathy, pericardial effusions, restrictive pericarditis) and congenital heart diseases (e.g., tricuspid dysplasia, ventricular and atrial septal defect) $(49,50)$. The analysis of these liquids can help in framing the ongoing pathological process.

The classifications of effusions, as recently proposed accordingly to underlie etiology, are clinically valuable and help the clinician to address to more specific diagnostic tests. Depending on the estimated total protein concentration and cytological criteria, effusions can be divided into four different groups: (a) transudate: can be rich or poor in protein; (b) exudate: can be septic or non-septic; (c) effusion caused by damaged vessels or viscus; and (d) effusion caused by cell exfoliation. Neoplastic outflow and reactive mesothelial hyperplasia are included in this last subgroup (51-53).

Protein-rich transudates due to increased hepatic or pulmonary intravascular hydraulic pressure may be caused by $\mathrm{CHF}$ and portal hypertension. Hallmarks of protein-rich transudates are a cloudy aspect, hemorrhagic aspect (but can also be clear), total protein (TP) concentration $\geq 2 \mathrm{~g} / \mathrm{dL}$, and presence of a variable number of neutrophils, lymphocytes, macrophages, and mesothelial cells. Effusions from cell exfoliation could derive from cardiac neoplasia as lymphoma, mesothelioma, carcinoma, and sarcoma ( $\mathrm{TP} \geq 2 \mathrm{~g} / \mathrm{dL}$ ). The term neoplastic effusion should be reserved for those fluids in which a neoplastic cell population has been evidenced (51-54).

\section{Vector-Borne Diseases}

Canine leishmaniasis is induced by the protozoan parasite Leishmania infantum. It is a systemic pathology with changeable clinical symptoms that can be diagnosed with IFAT, ELISA, real-time PCR, or direct visualization of the parasite through a microscope $(55,56)$. Cardiac involvement, associated with myocardial damage, has been reported postmortem, with histopathology, in some affected dogs $(57,58)$, and also by evidencing elevated values of cardiac troponin I (cTnI) in diseased patients (59).

The cause-effect connection in such dogs was initially hypothesized as a direct consequence of a primary myocardial damage due to azotemia; however, this thesis was disavowed, as high cTnI levels were diagnosed in leishmaniotic patients with normal renal azotemia while lower cTnI levels were found in cases with idiopathic CKD (60).

A research has evaluated the cardiotoxic effects of meglumine antimoniate for 60 days at therapeutic dosage in dogs with leishmaniasis, and it revealed that there was no demonstration in cTnI dosage or electrocardiographic characteristics of cardiac damage (61).

Ehrlichiosis is a canine vector-borne illness (tick) primarily induced by Ehrlichia canis, a gram-negative intracellular bacteria. IFAT, ELISA, and real-time PCR are diagnostic tests most frequently used to diagnose ehrlichiosis.

The mix of vasculitis, myocardial hemorrhages, and hypoperfusion accompanied by a strong inflammatory reaction participates in the pathophysiology of heart damage in dogs with ehrlichiosis. Furthermore, E. canis-infected dogs showed higher serum cTnI values than controls did $(62,63)$. In contrast, myocardial damage in canine monocytic ehrlichiosis and modification in serum cTnI or clinically important alterations in ECG or in echocardiographic parameters were not recorded in experimentally induced acute and subclinical disease (64).

\section{INNOVATIVE LABORATORY TEST}

\section{Cardiac Biomarker}

A biomarker would supply information concerning analysis, prognosis, or response to treatment that is otherwise not readily obtainable using usual testing; consequently, a cardiac biomarker can be considered as a substance that is heart specific and that is released during a disease status, proportionally to the extent of damage (65). The two most investigated cardiac biomarkers in dogs are cTnI and 2 different forms of B-type natriuretic peptide (BNP).

\section{Cardiac Troponin}

Cardiac troponin I (cTnI), along with troponin-T (cTnT) and troponin- $\mathrm{C}$, forms an aggregation of 3 myocardial proteins that 
are associated with the actin backbone inside myocardiocytes. Cardiac troponin I is a protein characteristic of cardiomyocyte involved in heart contraction and relaxation. It is attached to the actin filament, and it is present in moderate amount in the cytoplasm; therefore, the damage to cardiomyocytes leads to an extracellular release of cTnI (66-68); for this reason, an increase in its concentration may suggest a cardiac damage. Nevertheless, interestingly, Greyhounds and Boxers may possibly have inherently higher cTnI concentrations than other breeds (67-70).

In human patients, little to no cardiac troponin is noticeable in blood. Quantification of cardiac troponins may facilitate in quantifying the level of myocardial injury, supervise progression of diseases, and provide prognostic information in heart seizure patients. After a cardiac insult, an increase in these molecules might be found after $2-3 \mathrm{~h}$, and a peak concentration is commonly reached between 18 and $24 \mathrm{~h}$ (71-75). Severe myocardial infarction in canine is not common as it is probably due to the rare occurrence of atherosclerosis in dogs $(67,76,77)$. Nevertheless, chronic heart diseases like canine MVD and DCM are relatively common. Unfortunately, different causes might limit the utilization of cardiac troponin for veterinary patients; indeed, it is a sensitive but not specific marker. Cardiac troponin is partly removed by renal excretion; therefore, kidney disease can result in false increments $(67,78,79)$.

In dogs, cardiac troponins might be released into the bloodstream in reaction to inflammation. High cTnI concentrations have been detected in dogs with MVD, and this increase was proportional to the severity degree of the MVD. Many substantial associations of age, CRP, heart rate, and left ventricular end-diastolic diameter on cTnI concentration were also present $(67,80)$.

MVD is not the only disease that has been associated with myocardial injury and increased troponins; among these, there are subaortic stenosis, pulmonic stenosis, DCM, arrhythmogenic right ventricular cardiomyopathy, myocarditis, dirofilariasis, cardiac hemangiosarcoma, and pericardial effusion (69, 80-93).

Myocarditis is a condition that recognizes different etiologies, such as Leishmania infantum, Ehrlichia canis, Borrelia burgdorferi, Staphylococcus aureus, and does not recognize a specific course $(59,94)$. A study has found 6 dogs with myocarditis seropositive for Borrelia burgdorferi and increased amounts of cTnI (94).

Myocardial injury associated with increased cTnI has also been described in many non-cardiac diseases such as pancreatitis, pyometra, parvoviral enteritis, leptospirosis, leishmaniasis, babesiosis, and ehrlichiosis (67).

\section{Natriuretic Peptides}

Natriuretic peptides are hormones generated inside and released from the ventricular and atrial myocardium. Mechanical stress and cardiac muscle stretching are causes of prohormones released from the cardiac muscle (79). Stress or stretch of the myocardium, in response to volume excess or other conditions, increases the generation of prohormones pro B-type natriuretic peptide (proBNP) and pro-atrial natriuretic peptide (proANP). The prohormones can be divided into inactive N-terminal fragments (NTproANP or NTproBNP) and active C-terminal fragments (ANP and BNP) (79).

Active atrial natriuretic peptide (ANP) and BNP are involved in cardiovascular homeostasis as they inhibit the reninangiotensin-aldosterone mechanism, encourage vasodilatation by promoting natriuresis and diuresis, and reduce arterial blood pressure (1). BNP and NT-proBNP are increased in a very wide range of heart diseases, including MVD, DCM, and HCM (79, $81,95,96)$. Increased concentrations are also present in noncardiac diseases but can affect the heart, such as in $\mathrm{PH}$ (97). More precisely, a high concentration of NT-proBNP can be suggestive of HF, whereas a low concentration is most consistent with a noncardiac disease (78). NT-proBNP assay can be used for detecting dogs with occult DCM if combined with Holter monitoring with a sensitivity of $94.5 \%$ and specificity of $87.8 \%$ (98).

Very interestingly, there are also several studies revealing a correlation between NT-proBNP and survival time in dogs with $\operatorname{MVD}(99,100)$.

The reference intervals of cardiac biomarkers (as for all laboratory tests) may vary depending on the type of test used, sensitivity, and working conditions; therefore, it is hard to define a unique value of these. Some reviews have provided reference intervals for the various tests available $(67,68,79,101)$.

\section{Proteomics}

Proteomics is the study of the "proteome," that is, the whole of the protein, as for example in a specific district of the body or tissue (102). Cardioproteomics in humans has recently been introduced as a possible way to investigate cardiovascular diseases (103).

Around proteomics, there is growing interest as it has proven to be useful for clearing complex cellular and molecular phenotypes and has shown to have some possibility to detect circulating biomarkers and drug targets for therapeutic intervention. Although cardioproteomics could still be considered as a recent application of proteomics, interesting and promising results have already been achieved, in both humans and dogs. A recent study aiming at finding new biomarkers, by a proteomic approach, for mitral regurgitation due to mitral valve prolapse in humans showed that haptoglobin, platelet basic protein, and C4b levels could be reduced in these subjects, and therefore, a possible role in the pathophysiology of mitral valve prolapse/mitral regurgitation has been hypothesized for these molecules (and pathways in which are involved) (104).

As already said, proteomics also stimulates the interest of veterinary research and different substrates and diseases are increasingly being investigated $(105,106)$. In Cavalier King Charles Spaniels, a study on serum proteins evidenced different expressions in healthy dogs when compared with those in patients suffering from MVD, from mild to severe degrees. Complement factor $\mathrm{H}$ isoform 2, calpain-3 isoform $\mathrm{X} 2$, dystrobrevin beta isoform X7, and CD5 molecule-like and hydroxyglutarate dehydrogenase showed to be reduced in mildly affected patients when compared to controls. All these proteins, with the exclusion of complement factor $\mathrm{H}$, decreased accordingly to disease progression, showing in this way their potential in diagnosing and monitoring the disease (107). 


\section{Microbiota}

Intestinal microbiota (the set of bacteria, fungi, archaea, viruses, and protozoa) plays an important role in both health and disease states, regarding not only the gastrointestinal environment but also other districts of the body. Animal models play an important role in understanding the significance of gut microbiome configuration in immune system growth and its own relationship with health and disease (108). Furthermore, altered structure of gut microbiota, also called dysbiosis, participates in the genesis of some illnesses of the host (109).

In patients with $\mathrm{HF}$, intestinal function and role are abnormal due to microcirculatory disorders, and it could be evidenced in a rise in pathogenic bacteria in feces, and in the number of mucosal adherent bacteria in the colon, which is also linked to an increase in intestinal permeability $(110,111)$. Patients with $\mathrm{HF}$ recognize significantly altered gut microbiota, and its composition in older HF patients is dissimilar from that of younger HF patients (112). Similarly, hypertension, one of the most relevant predisposing factors to cardiovascular disease, has been linked to microbiota (113).

Unfortunately, this aspect is almost ignored in canine medicine, but as shown by a recent pilot study on a selected fecal

\section{REFERENCES}

1. Hall RL, Bender HS. Muscle. In: Latimer KS, editor. Duncan \& Prasse's Veterinary Laboratory Medicine: Clinical Pathology. Iowa, IA: Wiley e Blackwell V (2011). p. 283-94.

2. Stockham SL, Scott MA (editors). Enzymes. In: Fundamentals of Veterinary Clinical Pathology. 2nd ed. Iowa, IA: Blackwell Publishing Ltd (2008). p. 640-69.

3. Ridker PM. Clinical application of C-reactive protein for cardiovascular disease detection and prevention. Circulation. (2003) 107:363-9. doi: 10.1161/01.CIR.0000053730.47739.3C

4. Liquori ME, Christenson RH, Collinson PO, Defilippi CR. Cardiac biomarkers in heart failure. Clin Biochem. (2014) 47:327-37. doi: 10.1016/j.clinbiochem.2014.01.032

5. Ceron JJ, Eckersall PD, Martinez-Subiela S. Acute phaseproteins in dogs and cats: current knowledge and future perspectives. Vet Clin Pathol. (2005) 34:85-9. doi: 10.1111/j.1939-165X.2005.tb00019.x

6. Venco L, Bertazzolo W, Giordano G, Paltrinieri S. Evaluation of Creactive protein as a clinical biomarker in naturally heartworm-infected dogs: a field study. Vet Parasitol. (2014) 206:48-54. doi: 10.1016/j.vetpar. 2014.08.018

7. Barsanti JA. Urinary disorders. In: Willard MD, Tvedten H, editors. Small Animal: Clinical Diagnosis by Laboratory Methods. St Louis, MO: Elsevier (2012) p. 125-55. doi: 10.1016/B978-1-4377-0657-4.00007-7

8. Boswood A. Laboratory test. In: Fuentes V, Johnson LR, Dennis S, editors. BSAVA Manual of Feline and Canine Cardiorespiratory Medicine. 2nd ed. Gloucester, UK (2010). p. 60-6. doi: 10.22233/9781905319534.8

9. Di Bartola SP. Electrolyte and acid-base disorders. In: Willard MD, Tvedten H, editors. Small Animal: Clinical Diagnosis by Laboratory Methods. St Louis, MO: Elsevier (2012). p. 112-24. doi: 10.1016/B978-1-4377-0657-4.00006-5

10. Stockham SL, Scott MA (editors). Urinary system. In: Fundamentals of Veterinary Clinical Pathology. 2nd ed. Iowa, IA: Blackwell Publishing Ltd (2008). p. 416-87.

11. Ronco C, Haapio M, House AA, Anavekar N, Bellomo R. Cardiorenal syndrome. J Am Coll Cardiol. (2008) 52:152739. doi: 10.1016/j.jacc.2008.07.051

12. Ronco C, McCullough P, Anker SD, Anand I, Aspromonte N, Bagshaw $\mathrm{SM}$, et al. Cardio-renal syndromes: report from the consensus conference bacterial group in dogs suffering from cardiovascular diseases, suggesting possible differences between diseased and healthy dogs, it represents a very promising field of study (114).

\section{CONCLUSION}

This manuscript reviews the published data regarding the importance of laboratory tests and biomarkers in cardiac diseases. The aim of this manuscript is to underline that traditional laboratory tests and biomarkers are significantly efficient tools for the management of patients with cardiac diseases. In addition, new frontier studies concerning proteomics and microbiota in heart diseases have also been reviewed.

\section{AUTHOR CONTRIBUTIONS}

AG, MC, GR, and VT contributed conception and design of the study. AF revised the section relative to cardiac disease. AG wrote the first draft of the manuscript. AS, BT, and AM provided critical revision. All authors contributed to the article and approved the submitted version. of the acute dialysis quality initiative. Eur Heart J. (2010) 31:70311. doi: 10.1093/eurheartj/ehp507

13. Ronco C, Di Lullo L. Cardiorenal syndrome. Heart Fail Clin. (2014) 10:25180. doi: 10.1016/j.hfc.2013.12.003

14. Pouchelon JL, Atkins CE, Bussadori C, Oyama MA, Vaden SL, Bonagura JD, et al. Cardiovascular-renal axis disorders in the domestic dog and cat: a veterinary consensus statement. J Small Anim Pract. (2015) 56:53752. doi: $10.1111 /$ jsap. 12387

15. Di Bartola S. Clinical approach and laboratory evaluation of renal disease. In: Ettinger SJ, Feldman EC, editors. Textbook of Veterinary Internal Medicine, 5th ed. Philadelphia, PA: WB Saunders (2000). p. 1600-14.

16. Martinelli E, Locatelli C, Bassis S, Crosara S, Paltrinieri S, Scarpa P, et al. Preliminary investigation of cardiovascular-renal disorders in dogs with chronic mitral valve disease. J Vet Intern Med. (2016) 30:16128. doi: 10.1111/jvim. 14524

17. Nicolle AP, Chetboul V, Allerheiligen T, Pouchelon JL, Gouni V, Tessier-Vetzel D, et al. Azotemia and glomerular filtration rate in dogs with chronic valvular disease. J Vet Intern Med. (2007) 21:9439. doi: 10.1111/j.1939-1676.2007.tb03047.x

18. Relford R, Robertson J, Clements C. Symmetric dimethylarginine improving the diagnosis and staging of chronic kidney disease in small animals. Vet Clin North Am Small Anim Prac. (2016) 46:941-60. doi: 10.1016/j.cvsm.2016.06.010

19. Silverberg DS, Wexler, Blum DM, Iaina A. The cardio renal anemia syndrome: correcting anemia in patients with resistant congestive heart failure can improve both cardiac and renal function and reduce hospitalizations. Clin Nephrol. (2003) 60:S93-102.

20. Levine J, Kalman L, Mayer KL, Fillit HM, Packer M. Elevated circulating levels of tumor necrosis factor in severe chronic heart failure. N Engl J Med. (1990) 323:236-41. doi: 10.1056/NEJM199007263230405

21. Weiss G, Goodnough LT. Anemia of chronic disease. N Engl J Med. (2005) 352:1011-23. doi: 10.1056/NEJMra041809

22. Andron AS, Katz SD, Lund L, LaManca J, Hudaihed A, Hryniewicz $\mathrm{K}$, et al. Hemodilution is common in patients with advanced heart failure. Circulation. (2003) 107:226-9. doi: 10.1161/01.CIR.0000052623. 16194.80

23. Volpe M, Tritto C, Testa U, Rao MAE, Martucci R, Mirante A, et al. Blood levels of erythropoietin in congestive heart failure and correlation 
with clinical, hemodynamic, and hormonal profiles. Am J Cardiol. (1994) 74:468-73. doi: 10.1016/0002-9149(94)90905-9

24. Yu IB, Huang HP. Prevalence and prognosis of anemia in dogs with degenerative mitral valve disease. Biomed Res Int. (2016) 2016:4727054. doi: 10.1155/2016/4727054

25. Ohad DG, Berkowitz J, Bdolah-Abram T. Is the cardiorenalanemia syndrome prevalent in dogs? Proceedings of ACVIM congress 2010. J Vet Intern Med. (2010) 24:672. doi: 10.1111/j.1939-1676.2010.0521.x

26. Levy WC, Mozaffarian D, Linker DT, Sutradhar SC, Anker SD, Cropp $\mathrm{AB}$, et al. The seattle heart failure model: prediction of survival in heart failure. Circulation. (2006) 113:1424-33. doi: 10.1161/ CIRCULATIONAHA.105.584102

27. Pocock SJ, Wang D, Pfeffer MA, Yusuf S, McMurray JJ, Swedberg KB, et al. Predictors of mortality and morbidity in patients with chronic heart failure. Eur Heart J. (2006) 27:65-75. doi: 10.1093/eurheartj/ehi555

28. Danese E, Lippi G, Montagnana M. Red blood cell distribution width and cardiovascular diseases. J Thorac Dis. (2015) 7:E402-11. doi: 10.3978/j.issn.2072-1439.2015.10.04

29. Hampole CV, Mehrotra AK, Thenappan T, Gomberg- Maitland M, Shah SJ. Usefulness of red cell distribution width as a prognostic marker in pulmonary hypertension. Am J Cardiol. (2009) 104:86872. doi: 10.1016/j.amjcard.2009.05.016

30. James W, Swann MA, Sudunagunta S, Heather L, Covey MA, English K, et al. Evaluation of red cell distribution width in dogs with pulmonary hypertension. J Vet Cardiol. (2014) 16:227-35. doi: 10.1016/j.jvc.2014.08.003

31. Faunt KK, Turk JR, Cohn LA, Dodam JR, Johnson KH. Isolated right - ventricular hypertrophy associated with severe pulmonary vascular apolipoprotein A1 - derived amyloidosis in a dog. J Am Anim Hosp Assoc. (1998) 34:35-7. doi: 10.5326/15473317-34-1-35

32. Randolph JF, Peterson ME, Stokol T. Erythrocytosis and polycythemia. In: Weiss DJ, Wardrop KJ, editors. Schalms Veterinary Hematology. Iowa, IA: Wiley and Blackwell (2010). p. 162-6.

33. Cook SM, Lothrop CD. Serum erythropoietin concentrations measured by radioimmunoassay in normal, polycythemic, and anemic dogs and cats. J Vet Intern Med. (1994) 8:18-25. doi: 10.1111/j.1939-1676.1994.tb03191.x

34. Barger AM. Erythrocyte morphology. In: Weiss DJ, Wardrop KJ, editors. Schalms Veterinary Hematology, Iowa, IA: Wiley and Blackwell (2010) p. $145-51$.

35. Tvedten H. Laboratory and clinical diagnosis of anemia. In: Weiss DJ, Wardrop KJ editors. Schalms Veterinary Hematology, Iowa, IA: Wiley and Blackwell (2010) p. 153-61.

36. Holland CT, Canfield PJ, Watson ADJ, Allan GS. Dyserythropoiesis, polymyopathy, and cardiac disease in three related English springer spaniels. J Vet Intern Med. (1991) 5:151-9. doi: 10.1111/j.1939-1676.1991. tb00942.x

37. Sykes JE, Kittleson MD, Pesavento P, Byrne BA, MacDonald KA, Chomel BB. Evaluation of the relationship between causative organisms and clinical characteristics of infective endocarditis in dogs: 71 cases (1992-2005). J Am Vet Med Assoc. (2006) 228:1723-34. doi: 10.2460/javma.228.11.1723

38. de Lorenzo F, Saba N, Kakkar VV. Blood coagulation in patients with chronic heart failure: evidence for hypercoagulable state and potential for pharmacological intervention. Drugs. (2003) 63:565-76. doi: 10.2165/00003495-200363060-00004

39. Marcucci R, Gori AM, Giannotti F, Baldi M, Verdiani V, Del Pace S, et al. Markers of hypercoagulability and inflammation predict mortality in patients with heart failure. J Thromb Haemost. (2006) 4:101722. doi: $10.1111 /$ j.1538-7836.2006.01916.x

40. Tarnow I, Falk T, Tidholm A, Martinussen T, Jensen AL, Olsen, et al. Hemostatic biomarkers in dogs with chronic congestive heart failure. J Vet Intern Med. (2007) 21:451-7. doi: 10.1111/j.1939-1676.2007.tb02989.x

41. Olsen LH, Kristensen AT, Häggström J, Jensen AL, Klitgaard B, Hansson H. Increased platelet aggregation response in cavalier king charles spaniels with mitral valve prolapse. J Vet Intern Med. (2001) 15:20916. doi: 10.1111/j.1939-1676.2001.tb02313.x

42. Tarnow I, Kristensen AT, Texel H, Olsen LH, Pedersen HD. Decreased platelet function in cavalier king charles spaniels with mitral valve regurgitation. J Vet Intern Med. (2003) 17:680-6. doi: 10.1111/j.1939-1676.2003.tb02500.x
43. Tarnow I, Kristensen A, Olsen L, Falk T, Haubro L, Pedersen LG, et al. Dogs with heart diseases causing turbulent high - velocity blood flow have changes in platelet function and von Willebrand factor multimer distribution. $J$ Vet Intern Med. (2005) 19:515-22. doi: 10.1111/j.1939-1676.2005.tb02720.x

44. Tripathi NK, Gregory CR, Latimer KS. Urinary system. In: Latimer KS, editor. Duncan \& Prasse's Veterinary Laboratory Medicine: Clinical Pathology. Iowa, IA: Wiley e Blackwell (2011). p. 253-82.

45. Ware WA. Acquired valve disease. In: Ware WA, editor. Cardiovascular Disease in Small Animal Medicine. London, UK: Manson Publishing London LTD (2007). p. 263-79.

46. Miller MW, Fox PR, Saunders AB. Pathologic and clinical features of infectious endocarditis. J Vet Cardiol. (2004) 6:35-43. doi: 10.1016/ S1760-2734(06)70056-X

47. Wall M, Calvert CA, Greene CE. Infective endocarditis in dogs. Compend Contin Educ Pract Vet. (2002) 24:614-25.

48. Sykes JE, Kittleson MD, Chomel BB, MacDonald KA, Pesavento PA. Clinicopathologic findings and outcome in dogs with infective endocarditis: 71 cases (1992-2005). JAVMA. (2006) 22811:1735-47. doi: 10.2460/javma.228.11.1735

49. Gompf RE. The history and physical examination. In: Tilley LP, Smith FWK, Oyama MA, Sleeper MM, editors. Manual of Canine and Feline Cardiology. 4th ed. St Louis, MO: Saunders (2008) p. 2-23. doi: 10.1016/B978-141602398-2.10001-4

50. Ware WA. Abdominal distension. In: Ware WA, editor. Cardiovascular Disease in Small Animal Medicine. London, UK: Manson Publishing London LTD (2007). p. 121-6

51. Stockham SL, Scott MA (editors). Cavitary effusion. In: Fundamentals of Veterinary Clinical Pathology. 2nd ed. Iowa, IA: Blackwell Publishing Ltd (2008). p. 831-68.

52. Dempsey SM, Ewing PJE. A review of the pathophysiology, classification, and analysis of canine and feline cavitary effusion. JAAHA. (2011) 47:111. doi: 10.5326/JAAHA-MS-5558

53. Gavazza A, Turinelli V, Lubas G. Effusion in the cat: classification of 396 fluids according to a problem-oriented scheme. Comp Clin Pathol. (2013) 22:517-21. doi: 10.1007/s00580-013-1684-x

54. Alleman AR. Abdominal, thoracic and pericardial effusion. Vet Clin Small Anim. (2003) 33:89-118. doi: 10.1016/S0195-5616(02)00057-8

55. Paltrinieri S, Solano-Gallego L, Fondati A, Lubas G, Gradoni L, Castagnaro $\mathrm{M}$, et al. Guidelines for diagnosis and clinical classification of leishmaniasis in dogs. J Am Vet Med Assoc. (2010) 236:1184-91. doi: 10.2460/ javma.236.11.1184

56. Solano Gallego L, Guadalupe M, Alek K, Cardoso L, Pennisi M, Ferrer L, et al. LeishVet guidelines for the practical management of canine leishmaniosis. Parasit Vectors. (2011) 4:86. doi: 10.1186/1756-3305-4-86

57. Torrent E, Leiva M, Segales J, Franch J, Peña T, Cabrera B, et al. Myocarditis and generalized vasculitis associated with leishmaniosis in a dog. J Small Anim Pract. (2005) 46:549-52. doi: 10.1111/j.1748-5827.2005.tb00285.x

58. Rosa FA, Leite JH, Braga ET, Moreira PR, Baltazar FH, Biondo AW, et al. Cardiac lesions in 30 dogs naturally infected with Leishmania infantum chagasi. Vet Pathol. (2014) 51:603-6. doi: 10.1177/0300985813493914

59. Silvestrini P, Piviani M, Alberola J, Rodriguez Cortes A, Planellas M, Roura X, et al. Serum cardiac troponin I concentrations in dogs with leishmaniasis: correlation with age and clinicopathologic abnormalities. Vet Clin Pathol. (2012) 41:568-74. doi: 10.1111/j.1939-165X.2012. 00467.x

60. Martinez-Hernandez L, Casamian-Sorrosal D, Barrera-Chacon R, CuestaGerveno JM, Belinchon-Lorenzo S, Gomez Nieto LC, et al. Comparison of myocardial damage among dogs at different stages of clinical leishmaniasis and dogs with idiopathic chronic kidney disease. Vet J. (2017) 221:15. doi: 10.1016/j.tvjl.2016.11.015

61. Luciani A, Sconza S, Civitella C, Guglielmini C. Evaluation of the cardiac toxicity of $\mathrm{N}$-methyl-glucamine antimoniate in dogs with naturally occurring leishmaniasis. Vet J. (2013) 196:119-21. doi: 10.1016/j.tvjl.2012. 08.013

62. Sainz A, Roura X, Miró G, Estrada-Peña A, Kohn B, Harrus, et al. Guideline for veterinary practitioners on canine ehrlichiosis and anaplasmosis in Europe. Parasit Vectors. (2015) 4:8-75. doi: 10.1186/ s13071-015-0649-0 
63. Diniz PPVP, de Morais HSA, Breitschwerdt EB, Schwartz DS. Serum cardiac troponin I concentration in dogs with Ehrlichiosis. J Vet Intern Med. (2008) 22:1136-43. doi: 10.1111/j.1939-1676.2008.0145.x

64. Kalogianni L, Koutinas CK, Theodorou K, Xenoulis PG, Suchodolski JS, Harrus S, et al. Cardiac troponin I concentrations, electrocardiographic and echocardiographic variables remained unchanged in dogs experimentally infected with Ehrlichia canis. Vet J. (2016) 217:109-11. doi: 10.1016/j.tvjl.2016.09.007

65. Biomarkers definitions Working Group. Biomarkers and surrogate endpoints: preferred definitions and conceptual framework. Clin Pharmacol Ther. (2001) 69:89-95. doi: 10.1067/mcp.2001.113989

66. O’Brien PJ, Smith DEC, Knechtel TJ, Marchak MA, Pruimboom- Brees I, Brees DJ, et al. Cardiac troponin is a sensitive, specific biomarker of cardiac injury in laboratory animals. Lab Anim. (2006) 40:15371. doi: 10.1258/002367706776319042

67. Langhorn R, Willesen JL. Cardiac troponins in dogs and cats. J Vet Intern Med. (2016) 30:36-50. doi: 10.1111/jvim.13801

68. Baisan RA, de Rosa A, Di Loria A, Vulpe V, Piantedosi D. Cardiac biomarkers in clinical practice of dog and cat - a review. Hum Vet Med. (2016) 8:50-8.

69. Baumwart RD, Orvalho J, Meurs KM. Evaluation of serum cardiac troponin I concentration in boxers with arrhythmogenic right ventricular cardiomyopathy. Am J Vet Res. (2007) 68:524-8. doi: 10.2460/ajvr. 68.5 .524

70. LaVecchio D, Marin LM, Baumwart R, Iazbik MC, Westendorf N, Couto CG. Serum cardiac troponin I concentration in retired racing greyhounds. J Vet Intern Med. (2009) 23:87-90. doi: 10.1111/j.1939-1676.2008.0237.x

71. La Vecchia L, Mezzena G, Zanolla L, Paccanaro M, Varotto L, Bonanno $\mathrm{C}$, et al. Cardiactroponin I as diagnostic and prognostic marker in severe heart failure. J Heart Lung Transplant. (2000) 19:64452. doi: 10.1016/S1053-2498(00)00120-0

72. Sobel BE, LeWinter MM. Ingenuous interpretation of elevated blood levels of macromolecular markers of myocardial injury: a recipe for confusion. J Am Coll Cardiol. (2000) 35:1355-8. doi: 10.1016/S0735-1097(00)0 0516-7

73. Horwich TB, Patel J, MacLellan WR, Fonarow GC. Cardiac troponin I is associated with impaired hemodynamics, progressive left ventricular dysfunction, and increased mortality rates in advanced heart failure. Circulation. (2003) 108:833-8. doi: 10.1161/01.CIR.0000084543.79097.34

74. Babuin L, Jaffe AS. Troponin: the biomarker of choice for the detection of cardiac injury. Can Med Assoc J. (2005) 173:1191-202. doi: 10.1503/ cmaj/051291

75. Eggers KM, Jaffe AS, Lind L, Lindahl B. Value of cardiac troponin I cutoff concentrations below the 99th percentile for clinical decision-making. Clin Chem. (2009) 55:85-92. doi: 10.1373/clinchem.2007.101683

76. Driehuys S, van Winkle TJ, Sammarco CD, Drobatz KJ. Myocardial infarction in dogs and cats: 37 cases (1985-1994). J Am Vet Med Assoc. (1998) 213:1444-8.

77. Kidd L, Stepien RL, Amrheiw DP. Clinical findings and coronary artery disease in dogs and cats with acute and subacute myocardial necrosis: 28 cases. J Am Anim Hosp Assoc. (2000) 36:199-208. doi: 10.5326/ 15473317-36-3-199

78. Sharkey LC, Berzina I, Ferasin L, Tobias AH, Lulich JP, HegstadDavies RL. Evaluation of serum cardiac troponin I concentration in dogs with renal failure. J Am Vet Med Assoc. (2009) 234:76770. doi: 10.2460/javma.234.6.767

79. Oyama MA. Using cardiac biomarkers in veterinary practice. Clin Lab Med. (2015) 35:555-66. doi: 10.1016/j.cll.2015.05.005

80. Ljungvall I, Hoglund K, Tidholm A, Olsen LH, Borgarelli M, Venge P, et al. Cardiac Troponin I is associated with severity of myxomatous mitral valve disease, age, and C-reactive protein in dogs. J Vet Intern Med. (2010) 24:153-9. doi: 10.1111/j.1939-1676.2009.0428.x

81. DeFrancesco TC, Atkins CE, Keene BW, Coats JR, Hauck ML. Prospective clinical evaluation of serum cardiac troponin $\mathrm{T}$ in dogs admitted to a veterinary teaching hospital. J Vet Intern Med. (2002) 16:5537. doi: 10.1111/j.1939-1676.2002.tb02386.x

82. Oyama MA, Sisson DD. Cardiac troponin-I concentration in dogs with cardiac disease. J Vet Intern Med. (2004) 18:831-9. doi: 10.1111/ j.1939-1676.2004.tb02629.x
83. Tarducci A, Abate O, Borgarelli M, Borrelli A, Zanatta R, Cagnasso A. Serum values of cardiac troponin-T in normal and cardiomyopathic dogs. Vet Res Commun. (2004) 28:385-8. doi: 10.1023/B:VERC.0000045451. $89851.9 \mathrm{~d}$

84. Spratt D, Mellanby R, Drury N, Archer J. Cardiac troponin I: evaluation of a biomarker for the diagnosis of heart disease in the dog. J Small Anim Pract. (2005) 46:139-45. doi: 10.1111/j.1748-5827.2005.tb00304.x

85. Church WM, Sisson DD, Oyama MA, Zachary JF. Third degree atrioventricular block and sudden death secondary to acute myocarditis in a dog. J Vet Cardiol. (2007) 9:53-7. doi: 10.1016/j.jvc.2006.08.002

86. Oyama MA, Sisson DD, Solter PF. Prospective screening for occult cardiomyopathy in dogs by measurement of plasma atrial natriuretic peptide, B-type natriuretic peptide, and cardiac troponin-I concentrations. Am J Vet Res. (2007) 68:42-7. doi: 10.2460/ajvr.68.1.42

87. Saunders AB, Smith BE, Fosgate GT, Suchodolski JS, Steiner JM. Cardiac troponin I and C-reactive protein concentrations in dogs with severe pulmonic stenosis before and after balloon valvuloplasty. J Vet Cardiol. (2009) 11:9-16. doi: 10.1016/j.jvc.2009.04.002

88. Chun R, Kellihan HB, Henik RA, Stepien RL. Comparison of plasma cardiac troponin I concentrations among dogs with cardiac hemangiosarcoma, noncardiac hemangiosarcoma, other neoplasms, and pericardial effusion of nonhemangiosarcoma origin. J Am Vet Med Assoc. (2010) 237:80611. doi: 10.2460/javma.237.7.806

89. Guglielmini C, Civitella C, Diana A, Di Tommaso M, Cipone M, Luciani A. Serum cardiac troponin I concentration in dogs with precapillary and postcapillary pulmonary hypertension. J Vet Intern Med. (2010) 4:14552. doi: 10.1111/j.1939-1676.2009.0430.x

90. Wess G, Simak J, Mahling M, Hartmann K. Cardiac troponin I in doberman pinschers with cardiomyopathy. J Vet Intern Med. (2010) 24:8439. doi: 10.1111/j.1939-1676.2010.0516.x

91. Carreton E, Corbera JA, Juste MC, Juste MC, Mellado I, Morchón R, et al. Dirofilaria Immitis infection in dogs: cardiopulmonary biomarker levels. Vet Parasitol. (2011) 176:313-6. doi: 10.1016/j.vetpar.2011.01.015

92. Carreton E, Grandi G, Morchon R, Simón F, Passeri B, Cantoni $\mathrm{AM}$, et al. Myocardial damage in dogs affected by heartworm disease (Dirofilaria Immitis): immunohistochemical study of cardiac myoglobin and troponin I in naturally infected dogs. Vet Parasitol. (2012) 189:3903. doi: 10.1016/j.vetpar.2012.04.013

93. Falk T, Ljungvall I, Zois NE, Höglund K, Olsen LH, Pedersen HD, et al. Cardiac troponin-I concentration, myocardial arteriosclerosis, and fibrosis in dogs with congestive heart failure because of myxomatous mitral valve disease. J Vet Intern Med. (2013) 27:500-6. doi: 10.1111/jvim.12075

94. Janus I, Noszczyk-Nowak A, Nowak M, Cepiel A, Ciaputa R, Pasławska $\mathrm{U}$, et al. Myocarditis in dogs: etiology, clinical and histopathological features (11 cases: 2007-2013). Ir Vet J. (2014) 67:28. doi: 10.1186/ s13620-014-0028-8

95. Oyama MA, Fox PR, Rush JE, Rozanski EA, Lesser M. Clinical utility of serum N-terminal pro-B-type natriuretic peptide concentration for identifying cardiac disease in dogs and assessing disease severity. J Am Vet Med Assoc. (2008) 232:1496-503. doi: 10.2460/javma.232.10.1496

96. Connolly DJ, Magalhaes RJ, Syme HM, Boswood A, Fuentes VL, Chu L, et al. Circulating natriuretic peptides in cats with heart disease. J Vet Intern Med. (2008) 22:96-105. doi: 10.1111/j.1939-1676.2007.0024.x

97. Kellihan HB, Mackie BA, Stepien RL. NT-proBNP, NT-proANP and cTnI concentrations in dogs with pre-capillary pulmonary hypertension. J Vet Cardiol. (2011) 13:171-82. doi: 10.1016/j.jvc.2011.04.003

98. Singletary GE, Morris NA, O’Sullivan ML, Gordon SG, Oyama MA. Prospective evaluation of NTproBNP assay to detect occult dilated cardiomyopathy and predict survival in Doberman pinschers. J Vet Intern Med. (2012) 26:1330-6. doi: 10.1111/j.1939-1676.2012.1000.x

99. Chetboul V, Serres F, Tissier R, Lefebvre HP, Sampedrano CC, Gouni $\mathrm{V}$, et al. Association of plasma N-terminal pro-B-type natriuretic peptide concentration with mitral regurgitation severity and outcome in dogs with asymptomatic degenerative mitral valve disease. J Vet Intern Med. (2009) 23:984-94. doi: 10.1111/j.1939-1676.2009.0347.x

100. Moonarmart W, Boswood A, Luis Fuentes V, Brodbelt D, Souttar K, Elliott J. N-terminal pro B-type natriuretic peptide and left ventricular diameter independently predict mortality in dogs with mitral valve disease. 
J Small Anim Pract. (2010) 51:84-96. doi: 10.1111/j.1748-5827.2009.0 0889.x

101. Vieira de Lima G, da Silveira Ferreira F. N-terminal-pro brain natriuretic peptides in dogs and cats: a technical and clinical review. Vet World. (2017) 10:1072-82. doi: 10.14202/vetworld.2017.10 72-1082

102. Dhondalay GK, Rael E, Acharya S, Zhang W, Sampath V, Galli SJ, et al. Food allergy and omics. J Allergy Clin Immunol. (2018) 141:209. doi: 10.1016/j.jaci.2017.11.007

103. Cui Z, Dewey S, Gomes AV. Cardioproteomics: advancing the discovery of signaling mechanisms involved in cardiovascular diseases. Am J Cardiovasc Dis. (2011) 1:274-92.

104. Tan HT, Ling LH, Dolor-Torres MC, Yip JW, Richards AM, Chung MC. Proteomics discovery of biomarkers for mitral regurgitation caused by mitral valve prolapse. J Proteomics. (2013) 94:337-45. doi: 10.1016/j.jprot.2013.10.009

105. CanisOme. Available online at: http://salivatec.viseu.ucp.pt/canisome/ (accessed Dec 12, 2109).

106. Cerquetella M, Rossi G, Spaterna A, Tesei B, Gavazza A, Pengo $\mathrm{G}$, et al. Fecal proteomic analysis in healthy dogs and in dogs suffering from food responsive diarrhea. Sci World J. (2019) 2019:2742401. doi: 10.1155/2019/2742401

107. Locatelli C, Piras C, Riscazzi G, Alloggio I, Spalla I, Soggiu A, et al. Serum proteomic profiles in CKCS with Mitral valve disease. BMC Vet Res. (2017) 13:43. doi: 10.1186/s12917-017-0951-5

108. Suchodolski J. Diagnosis and interpretation of intestinal dysbiosis in dogs and cats. Vet J. (2016) 215:30-7. doi: 10.1016/j.tvjl.2016.04.011

109. Cho I, Blaser MJ. The human microbiome: at the interface of health and disease. Nat Rev Genet. (2012) 13:260-70. doi: 10.1038/ $\operatorname{nrg} 3182$

110. Sandek A, Bauditz J, Swidsinski A, Buhner S, Weber-Eibel J, von Haehling $S$, et al. Altered intestinal function in patients with chronic heart failure. J Am Coll Cardiol. (2007) 50:1561-69. doi: 10.1016/j.jacc. 2007.07.016

111. Sandek A, Swidsinski A, Schroedl W, Watson A, Valentova M, Herrmann R, et al. Intestinal blood flow in patients with chronic heart failure: a link with bacterial growth, gastrointestinal symptoms, and cachexia. J Am Coll Cardiol. (2014) 64:1092-102. doi: 10.1016/j.jacc.2014.06.1179

112. Kamo T, Akazawa H, Suda W, Saga-Kamo A, Shimizu Y, Yagi H, et al. Dysbiosis and compositional alterations with aging in the gut microbiota of patients with heart failure. PLoS ONE. (2017) 12:e0174099. doi: 10.1371/journal.pone.0174099

113. Marques FZ, Nelson E, Chu PY, Horlock D, Fiedler A, Ziemann $M$, et al. High-fiber diet and acetate supplementation change the gut microbiota and prevent the development of hypertension and heart failure in hypertensive mice. Circulation. (2017) 135:964-77. doi: 10.1161/CIRCULATIONAHA.116.024545

114. Gregori M, Silvi S, Copponi I, Fruganti A, Tambella A, Tesei B, et al. Evaluation of selected faecal bacterial groups with cardiovascular diseases in dogs. In: Proceedings SISVet LXXII. Torino. (2018) p. 321.

Conflict of Interest: VT was employed by company IDEXX.

The remaining authors declare that the research was conducted in the absence of any commercial or financial relationships that could be construed as a potential conflict of interest.

Copyright (C) 2020 Gavazza, Fruganti, Turinelli, Marchegiani, Spaterna, Tesei, Rossi and Cerquetella. This is an open-access article distributed under the terms of the Creative Commons Attribution License (CC BY). The use, distribution or reproduction in other forums is permitted, provided the original author(s) and the copyright owner(s) are credited and that the original publication in this journal is cited, in accordance with accepted academic practice. No use, distribution or reproduction is permitted which does not comply with these terms. 